\title{
O baú da República: mobilidades e memórias em Leite derramado
}

Tatiana Sena ${ }^{1}$

O romance Leite derramado, de Chico Buarque, foi publicado em 2009, exibindo uma estratégia editorial arrojada, que incluiu a criação de duas capas, texto de orelha do livro assinado pela crítica literária Leyla Perrone-Moisés e divulgação através de mídias sociais, além da participação do autor na Festa Literária Internacional de Parati (Flip) daquele ano, ao lado do escritor Milton Hatoum. O romance também foi destaque em resenhas dos principais suplementos literários brasileiros, obtendo análises elogiosas de críticos renomados.

Todos esses elementos agregaram ainda mais valor editorial ao lançamento do "novo livro do Chico", como o público leitor referia-se à obra, exprimindo as expectativas e as curiosidades em torno dela. Essa repercussão conduziu o livro à lista dos mais vendidos daquele ano, confirmando o êxito do romance, que, além disso, angariou os principais prêmios referentes ao ano de 2009, como o Portugal Telecom de Literatura (2010) e o Jabuti (2010) como "Livro do ano de ficção", embora tenha sido apenas o segundo colocado na categoria "Melhor romance", fato que desencadeou algumas polêmicas no universo literário brasileiro. ${ }^{2}$

O processo criativo de Leite derramado, segundo depoimentos de Chico Buarque em entrevistas, levou em consideração dois aspectos. O primeiro desafio seria diferenciar-se do romance anterior, Budapeste, aclamado pelo público e pela crítica. Se neste a preocupação foi conhecer outros lugares, em Leite derramado, o escritor buscou visitar outros tempos. O desejo pela investigação temporal encontrou em uma antiga composição musical, "O velho Francisco", a matriz narrativa que Chico Buarque utilizaria no novo romance. ${ }^{3}$ Nessa canção, o sujeito

\footnotetext{
${ }^{1}$ Doutoranda em Literatura Comparada no Programa Estudos Literários da UFMG, Belo Horizonte, Brasil. Bolsista CNPq. E-mail: tatianasena@ufmg.br

${ }^{2}$ O grupo editorial Record, em carta aberta, atribui a critérios "midiáticos” e "políticos” a escolha de Leite derramado como "Livro do ano", em detrimento do romance Se eu fechar meus olhos agora, de Edney Silvestre, publicado pela referida empresa e que havia obtido o primeiro lugar na categoria "Melhor romance".

${ }^{3}$ Segundo Wagner Homem (2009, p. 250), essa composição foi inspirada por um sonho que Chico Buarque tivera, descrito da seguinte forma ao jornalista Humberto Werneck: "Uma preta velha que
} 
enunciador é um velho escravo alforriado, que narra emaranhada e incertamente as peripécias de sua vida.

O modo de narrar dos velhos funciona como motivação formal e estilística na elaboração de Leite derramado, cuja técnica literária explora os decursos da memória, entrelaçando temporalidades pessoais e sociais. Como destacou Ecléa Bosi (1987), a memória dos velhos se distingue por seu interesse consciente pelo passado. Nesse processo de rememoração, desfigura o passado pela ação de filtros subjetivos diversificados.

Chico Buarque constrói uma narrativa em que as oscilações da memória individual do velho centenário Eulálio Montenegro d'Assumpção, narrador-protagonista do romance, podem ser lidas em contraposição aos lapsos da memória nacional da forma republicana, que em 2009, ano de publicação do romance, completou 120 anos de implantação. Os entrelaçamentos discursivos entre literatura, música, sociologia e história produzem uma sofisticada crítica aos impasses da República brasileira.

No romance, a história de declínio de uma família oligárquica repõe a questão da República, pelo prisma de uma narrativa derrisória. Chico Buarque retoma um motivo literário bastante produtivo nas literaturas latino-americanas, expondo as vicissitudes de uma saga familiar, alinhando-se assim a uma tradição literária que inclui Cem anos de solidão, de Gabriel García Marquez, e Viva o povo brasileiro, de João Ubaldo Ribeiro.

A história do Brasil encontra na literatura um espaço privilegiado de reinvenção, no qual a rememoração de episódios consagrados ou esquecidos da história nacional frequentemente possibilita a reativação diferencial de sentidos que se plasmam e se antagonizam na memória cultural do país, tornando visíveis conflitos, impasses e vozes recalcadas nas versões oficiais do discurso brasileiro.

Wolfgang Iser destacou que a presença do real é identificável no texto ficcional, mas que este não se esgota nessa referência. Para Iser, essa realidade replicada pode ser compreendida como "atos de fingir", cuja operação estabeleceria relações recíprocas entre o real, o fictício e o imaginário, através da "transgressão de limites" (Iser, 1996, p. 14) promovida pelo texto literário.

contava uma história num fundo de cozinha e pedia, com a voz cava e arrastada: 'Fecha a porta! Fecha a porta'”. 
Alicerçando-se nos postulados teóricos de Iser, é possível dizer que a realidade representada em Leite derramado recortou, selecionou, condensou e reorganizou referências de sistemas contextuais preexistentes, literários e sociais, colocando-se como uma forma de "acesso ao mundo" (Iser, 1996, p. 16).

Eulálio parece relatar sua história a mais de uma pessoa. Todavia, não sabemos ao certo se elas não são apenas imaginárias. Seus interlocutores mais recorrentes seriam uma suposta enfermeira e a filha Maria Eulália, mas ele também se dirige a pacientes nas enfermarias ou a qualquer passante nos corredores do hospital, assim como se dirige delirantemente à mãe morta. A ação do romance está compreendida entre os anos de 1907 e 2007, período do centenário de Eulálio. Porém, através de intensivas rememorações, Eulálio busca reconstituir uma ancestralidade que remontaria ao século XVI, conforme o seguinte excerto:

Então começo a recapitular as origens mais longínquas da minha família, e em mil quatrocentos e lá vai fumaça há registro de um doutor Eulálio Ximenez d'Assumpção, alquimista e médico particular de dom Manuel I. Venho descendo sem pressa até o limiar do século XX, mas antes de entrar na minha vida propriamente, faço questão de remontar aos meus ancestrais por parte de mãe, com caçadores de índios num ramo paulista, num outro guerreiros escoceses do clã dos McKenzie (Buarque, 2009, p. 184-185).

A despeito dessa prospecção genealógica, convém não perder de vista o pano de fundo da vida propriamente dita de Eulálio, que se desenrola do governo de Afonso Pena até a gestão do presidente Lula. As oscilações entre figura e fundo permitem analisar as interações entre sujeito e história social.

Sugestivamente, no aniversário de seu centenário, Eulálio recebe da namorada de seu tataraneto uma garrafa de Château Margaux 1989. Esse vinho francês, de safra datada de 1989, mesmo ano das comemorações pelo centenário da República no Brasil, parece ironizar a matriz política francesa, tão cara aos republicanos brasileiros, desdenhando assim das promessas não efetivadas de "liberdade, igualdade e fraternidade", como o Hino da República vaticinava, embora seus enunciadores nem cressem que "escravos outrora tenha havido em tão nobre país", como foi destacado por Lilia Schwarcz (2008).

Repensar a tradição republicana a partir da literatura abre um campo de problematização diferencial para as discussões em torno da formação 
política brasileira e, principalmente, acerca da própria literatura, de seus nexos e/ou atritos com a perspectiva hegemônica da modernização desenvolvimentista nacional executada pelos governos republicanos.

Em algumas obras literárias das últimas décadas, a exemplo de Dois irmãos, de Milton Hatoum, Cidade de Deus, de Paulo Lins, e O filho eterno, de Cristóvão Tezza, a presença em negativo da narrativa da República coloca em tensão os enredos através da irrupção de outras temporalidades, que compõem o tempo "heterogêneo, irregular e denso" da nação contemporânea (Chatterjee, 2004, p. 74). De maneira sugestiva, essas produções literárias trabalham com a ideia de outros Brasis e de outras repúblicas, percepção que encontra ressonâncias também em análises teóricas atuais.

Como destacou o pesquisador Newton Bignotto, muitos romances contemporâneos, centrados no universo urbano, retomarão tais questionamentos, a fim de "mostrar como a narrativa da República esteve presente ao longo do século XX como uma questão fundante de nossa experiência histórica, mesmo se o que constatamos é o enorme vazio que parece povoar nosso universo simbólico e imaginário" (Bignotto, 2000, p. 11).

Em vista do exposto anteriormente, buscarei acompanhar os decursos temporais e espaciais da trajetória de Eulálio Montenegro d'Assumpção, delineando uma "topoanálise dos espaços da intimidade" (Bachelard, 1978 , p. 253) desse velho centenário, a fim de entrecruzá-la com os espaços da história social. Como um arqueólogo dedicado, Eulálio desencava lembranças, a ponto de não saber "em qual camada da memória" (Buarque, 2009, p. 139) se encontrava. Por mais que esprema sua memória até o "bagaço", Eulálio garante que ainda tem na "cabeça um baú repleto de reminiscências inéditas" (p. 185). O baú de Eulálio guarda também lembranças e esquecimentos da República.

Os itinerários memorialísticos de Eulálio o conduzem à fazenda da infância, ao casarão de Botafogo, ao chalé de Copacabana, aos apartamentos, primeiramente no bairro de Copacabana e depois no bairro da Tijuca, e, finalmente, à casa de um cômodo na periferia da cidade do Rio de Janeiro. Essas estações da memória são percorridas através dos devaneios do narrador, preso à cama de um hospital público.

Como destacou Foucault em conferência em 1967, “a época atual seria talvez de preferência a época do espaço" (Foucault, 2009, p. 411). Nas últimas décadas do século $X X$, esse prognóstico mostrou-se 
acertado, confirmando o predomínio da categoria do espaço na vida comum dos indivíduos e na produção do saber contemporâneo, processo que concorreu para a disseminação de um vocabulário marcadamente espacial.

Como apontou Ferrara (2008), a noção de espaço é construída na contemporaneidade pelas interconexões entre comunicação e cultura. Segundo Cury, "as questões relativas ao espaço são de fundamental importância para a produção cultural" (Cury, 2007, p. 8). Em textos ficcionais contemporâneos, a cidade foi elaborada não apenas como tema mas também como motivo de investigação formal.

Em Leite derramado, os itinerários de Eulálio, predominantemente na cidade do Rio de Janeiro, são bem eloquentes das mobilidades espaciais, subjetivas e sociais, configurando-se como uma errância, que pode ser compreendida a partir da "ideia de deslocamento físico ou mental, voluntário ou involuntário", conforme assinalou Olivieri-Godet (2010, p. 189). No caso de Eulálio, sua errância é negativa e involuntária.

A narração principia com uma promessa: "Quando eu sair daqui, vamos nos casar na fazenda da minha feliz infância, lá na raiz da serra" (Buarque, 2009, p. 5). Nesse período, existem duas indicações espaciais relevantes para a compreensão sobre quem narra a história. A primeira delas é o advérbio de lugar "daqui", a segunda indicação é a fazenda.

No longo parágrafo, que forma todo o primeiro capítulo, a localização dêitica é esclarecida. O narrador se encontra internado em um hospital. Diferente dos narradores tradicionais, na análise de Walter Benjamin (1994), nem mesmo a proximidade com a morte garante a Eulálio Montenegro d'Assumpção autoridade narrativa, visto que o discurso crítico da obra, elaborado indiretamente, concorre para questioná-lo. Como apontou Schwarz, a montagem do romance deixa visíveis as fissuras da "autoexposição 'involuntária' de um figurão", acrescentando ainda que o "pressuposto dessa solução formal" exige uma "certa conivência maldosa entre o autor e o leitor esperto" (Schwarz, 2009).

Chico Buarque apoia-se também no sistema contextual literário, já que o "figurão" foi um tipo de personagem bastante explorado nas obras de Machado de Assis. Através dessa elaboração literária, é possível abordar "o homem da elite brasileira que detinha certo conhecimento livresco e que tentava obter vantagens imaginárias e reais apoiado nisso, restando, no entanto, o conflito de estar sempre isolado num país periférico" (Lima, 2010, p. 1169). 
Sua condição de enfermo situa-o numa posição limiar entre os "dois reinos", pensando-se na leitura de Susan Sontag, para quem "a doença é o lado sombrio da vida, uma espécie de cidadania mais onerosa", existindo assim uma "dupla cidadania, no reino dos sãos e no reino dos doentes" (Sontag, 2007, p. 11). Nesse lugar extremo, o narrador desvincula-se das exigências sociais e pode falar sem restrições sobre o que pensa e sente. Por estar acamado, numa quase imobilidade, o narrador confidencia: "[É] triste ser abandonado assim falando com o teto" (Buarque, 2009, p. 139).

É possível compreender o exercício rememorativo de Eulálio através da categoria de "intra-moção", na expressão cunhada por Nubia Hanciau e que Cury retomou para falar de

romances que, tematizando deslocamentos espaciais (e temporais), também encenam uma busca subjetiva, um movimento "para dentro" na busca do espaço interior de seus narradores e personagens/protagonistas, discursos de memória em que estranhamente é a representação do presente o objeto de disputa (Cury, 2007, p. 12).

A rememoração coordena simultaneamente o movimento introspectivo e o movimento retrospectivo, retirando o narrador da inércia e da apatia que o internamento prolongado ocasiona. Eulálio movimenta-se numa trajetória para dentro e para trás e perde-se em rotas interiores, palmilhando antigas paisagens de um passado reconstituído.

A partir da concepção benjaminiana de alegoria como ruína, é possível dizer que as temporalidades inscritas em Leite derramado plasmaram imagens derrisórias, recuperadas pela memória e revistas com avidez por Eulálio. Segundo Benjamin, "como ruína, a história se fundiu sensorialmente com o cenário. Sob essa forma, a história não constitui um processo de vida eterna, mas de inevitável declínio" (Benjamin, 1984, p. 200).

A linguagem alegórica diz o outro pelo que falta, pela perda, impossibilitando o fechamento do sentido do texto. Como ressaltou Jeanne-Marie Gagnebin, “a linguagem alegórica extrai sua profusão de duas fontes que se juntam num mesmo rio de imagens: da tristeza, do luto provocado pela ausência de um referente último; da liberdade lúdica, do jogo que tal ausência acarreta para quem ousa inventar novas leis transitórias e novos sentidos efêmeros" (Gagnebin, 1994, p. 45). Em Leite derramado, luto e jogo (re)ativam imagens pretéritas e confundidas da história de Eulálio e da história da República no Brasil. 
A doença de Eulálio pode ser entendida como uma alegoria para o estado terminal de uma mentalidade obsoleta, alicerçada em valores provenientes de instituições coloniais, cujo patriarcalismo e escravismo instituíram o "romance doméstico" brasileiro (Sommer, 2004). No hospital, local limite, Eulálio narra o declínio, a morte, a ruína. Por isso, sua promessa no início da narrativa dirige-se para a fazenda onde viveu uma infância que considera feliz, justamente por ainda estar intacta a visão de mundo norteadora de sua existência.

Como a narrativa de Eulálio evidencia, através de sua suposta promessa a uma enfermeira que talvez o ouvisse, a fazenda era um espaço de prestígio e de poder. Ele expõe em minúcias as regalias de que ela iria dispor, caso aceitasse sua proposta: "Você vai dispor dos rendados, dos cristais, da baixela, das joias e do nome da minha família. Vai dar ordens aos criados" (Buarque, 2009, p. 5). Em outra passagem, o narrador acrescenta:

Meu avô foi um figurão do Império, grão-maçom e abolicionista radical, queria mandar todos os pretos brasileiros de volta para a África, mas não deu certo. Seus próprios escravos, depois de alforriados, escolheram permanecer nas propriedades dele. Possuía cacauais na Bahia, cafezais em São Paulo, fez fortuna, morreu no exílio e está enterrado no cemitério familiar da fazenda na raiz da serra, com a capela abençoada pelo cardeal arcebispo do Rio de Janeiro. Seu ex-escravo mais chegado, o Balbino, fiel como um cão, ficou sentado para sempre sobre a tumba dele (Buarque, 2009, p. 15-16).

A fazenda da serra é a relíquia do avô e a marca do passado colonial e imperial, monumento de uma configuração de poder marcadamente racista. A partir das contribuições teóricas de Foucault (1999, 2008), compreendo o racismo como um dispositivo biopolítico, que permitiu ao Estado moderno exercer a função de morte. Na teoria clássica da soberania, o direito de vida e de morte sobre o súdito pertencia ao soberano. Entretanto a soberania como modalidade de poder seria ineficiente para reger uma sociedade em via de industrialização. Para Foucault,

uma das mais maciças transformações do direito político do século XIX consistiu, não digo exatamente em substituir, mas em completar esse velho direito de soberania - fazer morrer ou deixar viver - com outro direito novo, que não vai apagar o primeiro, mas vai penetrá-lo, perpassá-lo, modificá-lo, e que vai 
ser um direito, ou melhor, um poder exatamente inverso: poder de "fazer" viver e de "deixar" morrer (Foucault, 1999, p. 287).

Dessa forma, fizeram-se necessárias duas acomodações dos mecanismos de poder: a primeira disciplinadora (tecnologia disciplinar) e a segunda reguladora (tecnologia biopolítica), ambas centradas no corpo. Esse processo concorreu para a formação de um discurso específico, cuja linguagem codificou moralmente os traços fenotípicos diferenciais, a fim de regulamentar um efeito político.

Embora a fazenda seja um local constantemente relembrado na moderna literatura brasileira, como é o caso de Menino de engenho, de José Lins do Rego, são tornadas invisíveis as marcas da violência e do terror escravista, que acabam por se inscrever fantasmaticamente na narrativa álacre do ponto de vista senhorial.

A riqueza da família Assumpção foi construída através do tráfico escravagista, tendo sido seu bisavô um "barão negreiro" (Buarque, 2009, p. 62), envolvido na captura de "peças" em Moçambique, embora o narrador faça questão de enfatizar que "o dinheiro dos Assumpção sempre foi limpo" (Buarque, 2009, p. 78). A insígnia desse poder está materializada no chicote com correia trançada de couro de antílope e com uma flor-de-lis gravada no cabo, considerada uma "relíquia familiar" (Buarque, 2009, p. 102), transmitida através de gerações.

Significativamente, o pai de Eulálio guardava esse chicote na biblioteca, "atrás da enciclopédia Larousse" (Buarque, 2009, p. 102). A flor-de-lis é um símbolo francês e adornava instrumentos de torturas do terror escravista. O Código Negro (Code Noir), instituído por Luís XIV, no seu artigo 38, prescrevia como punição para escravos fugitivos a marcação em brasa da flor-de-lis nas costas.

Chico Buarque aproxima-se de Machado de Assis na perlaboração da memória da escravidão, destacando sua resiliência, haja vista "os passados não ditos, não representados, que assombram o presente histórico" (Bhabha, 2005, p. 34). Não se pode perder de vista que a escravidão como instituição social organizou a vida econômica e política na terra que viria a ser designada como Brasil desde o século XVI.

Se "a escravidão levou consigo aparelhos e ofícios", como ironicamente sugeriu Machado de Assis, em 1906, no conto "Pai contra mãe", bem mais duradouros se mostram os valores e as práticas que estruturaram aquela instituição social, visto que, extinta por decreto, 
seus códigos e sistemas não deixaram de lastrear o cotidiano brasileiro nos contextos pós-abolicionistas, reemergindo em formas diferenciadas.

Em Leite derramado, existe uma "negação de contemporaneidade" (Fabian apud Mignolo, 1995, p. 11) evidente na relação intersubjetiva entre as gerações de Eulálios e Balbinos. O narrador relembra os açoites que o avô infligia ao "velho Balbino":

O Balbino nem era mais escravo, mas dizem que todo dia tirava a roupa e se abraçava num tronco de figueira, por necessidade de apanhar no lombo. E vovô batia de chapa, sem malícia na mão, batia mais pelo estalo que pelo suplício. Se quisesse lanhar, imitaria seu pai, que quando pegava negro fujão, açoitava em grande estilo. O golpe mal estalava, era um assobio no ar o que se ouvia, meu bisavô Eulálio apenas riscava a carne do malandro com a ponta da correia, mas o vergão ficava sempre (Buarque, 2009, p. 102).

No romance Leite derramado, as construções subjetivas pautadas na relação com o outro subalterno são inegáveis. Como o narrador explica, o escravo Balbino adotou o sobrenome Assunção, "na forma assim mais popular, [...] como a pedir licença para entrar na família sem sapatos" (Buarque, 2009, p. 18), acrescentando que "[c]urioso é que seu filho, também Balbino, foi cavalariço do meu pai. E o filho deste, Balbino Assunção Neto, um preto meio roliço, foi meu amigo de infância" (Buarque, 2009, p. 18). A "amizade" entre os dois foi construída na fazenda, onde Eulálio pedia um "favor à-toa", a fim de agradar a "índole prestativa" de Balbino (Buarque, 2009, p. 19). ${ }^{4}$

Discursos históricos, como os escritos de um ilustre abolicionista, podem ajudar a compreender como, mesmo para aqueles favoráveis à "emancipação", a dependência subjetiva do escravo era inegável. Em O Abolicionismo, ensaio publicado em 1883, por exemplo, Joaquim Nabuco afirmou que a emancipação dos escravos garantiria "a eliminação simultânea dos dois tipos contrários, e no fundo os mesmos: o escravo e o senhor" (Nabuco, 2003, p. 39). O mesmo Nabuco, em Minha formação, autobiografia publicada em 1900, confidenciaria que, extinta a escravidão, experimentou uma "nostalgia singular", traduzida como "saudade do escravo" (Nabuco, 1900, p. 216).

\footnotetext{
${ }^{4}$ Impossível não ressaltar a repetição dessa cena formativa em Memórias póstumas de Brás Cubas, designadamente no capítulo "O menino é pai do homem”, no qual Brás Cubas se dispõe a explicitar alguns lineamentos da sua infância, de como cresceu "naturalmente”.
} 
Em Leite derramado, embora a miragem fausta da fazenda tenha se esboroado: "E mesmo a fazenda na raiz da serra, acho que desapropriaram em 1947 para passar a rodovia" (Buarque, 2009, p. 7), as configurações de poder engendradas no contexto colonial e imperial lastreiam, de maneira diferenciada, o cotidiano da República.

É extremamente significativo que a instituição da forma republicana tenha acontecido no ano seguinte à Abolição. A Proclamação da República marcou um ponto de inflexão na história política brasileira, visto que a opção pela simbologia do progresso e do futuro ficou evidente, assim como ficou explícito o recalcamento da memória da escravidão, como um passado a ser totalmente esquecido. A memória da escravidão é um fantasma na narrativa nacional republicana.

Em vista disso, vale a pena acompanhar as idas e vindas da memória senhorial plasmada por Eulálio. Da grande fazenda à casa de um só cômodo no subúrbio, delineia-se uma mobilidade descensional. Leite derramado é mais uma narrativa da decadência. Chico Buarque insere-se, diferencialmente, numa tradição literária bastante fecunda na literatura brasileira, como já Antonio Candido destacou: "Sempre me intrigou o fato de um país novo como o Brasil, e num século como o nosso, a ficção, a poesia, o teatro produzirem a maioria das obras de valor no tema da decadência - social, familiar, pessoal" (Candido, 1979, p. VII).

Embora a voz narrativa pertença a um herdeiro nostálgico de seu prestígio, a construção discursiva do romance não referenda essa perspectiva, explicitando os dilemas éticos nessa trajetória em que a proeminência autoatribuída não condiz mais com o tratamento recebido por outras pessoas.

Outra estação nesse itinerário rememorativo é o casarão neoclássico de Botafogo, construído pelo pai de Eulálio, resíduo da belle époque da República Velha. O luxo e a ostentação objetivam civilizar o Rio de Janeiro pela reprodução de um modelo urbano cuja referência é a França. Como o narrador faz questão de descrever: "Ali há quartos enormes, banheiros de mármore com bidês, vários salões com espelhos venezianos, estátuas, pé-direito monumental e telhas de ardósia importadas da França" (Buarque, 2009, p. 6).

Assim como a fazenda, o casarão não existe mais enquanto tal, como Eulálio depois recorda: "Há palmeiras, abacateiros e amendoeiras no jardim, que virou estacionamento depois que a embaixada da Dinamarca mudou para Brasília" (Buarque, 2009, p. 6). Eulálio registra 
as perdas e as transformações dos locais onde sua memória perscruta as imagens do passado: "Aliás, bem em cima do nosso próprio terreno levantaram um centro médico de dezoito andares, e com isso acabo de me lembrar que o casarão não existe mais" (Buarque, 2009, p. 6).

O pai de Eulálio foi um "notável da República" (Buarque, 2009, p. 57), para quem as portas estiveram "apenas encostadas", devido ao nome influente da família, Assumpção, com " $\mathrm{p}$ " mudo, para diferenciar-se dos "populares" como Balbino. Contudo, o espólio da família Assumpção foi liquidado com a quebra da Bolsa de Nova York, iniciando o declínio financeiro.

Dentre todos os espaços que Eulálio revisita na narração, o chalé de Copacabana é o seu "lugar de memória" (Nora, 1993) por excelência, consagrado à lembrança de Matilde, "uma garota incrivelmente desejável, feita de quase nada", como a descreveu Schwarz (2009). Porém, justamente por essa evanescência, Matilde é obsessivamente perseguida por Eulálio, que insiste em reter seu corpo e fixar sua imagem. Depois de casados, foram viver no chalé, onde se agarravam "na cozinha, na sala, na escada, horas e horas no banho" (Buarque, 2009, p. 63).

Após a inexplicável desaparição de Matilde, a lembrança da esposa o assaltava em cada cômodo da casa, para onde levou algumas mulheres, que inclusive usaram a roupa de Matilde, numa tentativa de preencher o vazio provocado pela sua ausência. Sem a mulher, "o chalé outrora tão solar foi se deteriorando" (Buarque, 2009, p. 94), rodeado pelos edifícios altos e luxuosos que requalificaram urbanisticamente o bairro de Copacabana. A despeito dessas transformações na paisagem, era "a sombra de Matilde" (Buarque, 2009, p. 94) que Eulálio via projetada sobre o chalé.

Por insistência da filha, Maria Eulália, que desde a adolescência achava "meio jeca" morar numa casa com quintal, Eulálio desfaz-se do chalé: "Então me rendi, vendi a residência dos meus sonhos" (Buarque, 2009, p. 124). Dessa residência, o narrador conservou a mobília antiga, o retrato do avô e, como confidenciou: "[A]pós alguma hesitação, levei também o armário com os vestidos da minha mulher, o criado-mudo com suas joias na gaveta" (p. 124).

Na demolição do chalé, a casa, o corpo e as lembranças do narrador se confundem, numa amálgama afetivo. As residências arruinadas fazenda, casarão, chalé - compõem uma geografia imaginária de escombros, que o narrador revolve, à procura dos fragmentos de uma felicidade pretérita. 
Da janela do meu prédio vizinho, eu assistira à demolição do chalé, vi cheio de pudor meu quarto com Matilde destelhado, vi ruir nossa laje, nossas paredes se desmanchando em pó e as fundações quebradas à picareta. No lugar dele subiu um edifício modernista, tomei por uma delicadeza do arquiteto a construção suspensa sobre pilotis, para não soterrar de vez minhas recordações (Buarque, 2009, p. 151).

A arquitetura modernista substitui a arquitetura neoclássica da primeira remodelação urbana realizada pelo governo republicano, marcando um novo ponto de inflexão da empreitada modernizadora do país. A nova arquitetura funcionalista, de matriz corbusieana, é a expressão do futuro nos projetos de Lúcio Costa e Oscar Niemeyer. As edificações, elevadas por pilotis, projetam-se no espaço como imponentes marcos dos artifícios modernizantes.

Todavia, Eulálio estava preso às casas antigas, de tempos passados. Com a demolição do chalé, Eulálio mudou-se para um edifício de apartamentos, não sem muita resistência, já que considerava essas habitações "promíscuas". É o fim da exclusividade, por mais luxuoso que seja o condomínio, por mais que supostamente se esteja entre pares, já que a lógica dos signos de distinção não é mais a mesma. Uma cena é exemplar desses estranhamentos:

O edifício tem lá sua classe, com o hall de entrada metido a art déco, os vizinhos são discretos, os porteiros limpinhos. Trata-se enfim de um ambiente seleto, e era natural que me causasse espécie entrar comigo no elevador um grandalhão com cara de nortista, nariz chato, pele grossa. Indiquei-lhe o elevador de serviço, mas ele me deu as costas e apertou o botão do meu oitavo andar (Buarque, 2009, p. 141-142).

O grandalhão com cara de nortista era um "jogador de futebol meio caboclo" (Buarque, 2009, p. 143) e não apenas se dirigia ao andar "dele" como também namorava sua filha Maria Eulália. Todavia, esse apartamento na Zona Sul ficaria para trás, substituído por um apartamento na Tijuca, bairro da Zona Norte, já que Eulálio começou a ser desprezado socialmente, além de ter recebido queixas do condomínio, como explicou o narrador: "Porque o Xerxes, quando bebia, costumava bater na minha filha, mas em bairros mais populares cenas do gênero são corriqueiras, não escandalizam ninguém" (p. 143). 
O apartamento da Tijuca seria arrombado pela polícia, à procura do neto comunista, alvo da repressão da ditadura militar. Posteriormente, Eulálio foi desapropriado desse apartamento, devido à cobrança de uma dívida contraída pelo seu tataraneto, que dera o imóvel como caução ao agiota, pastor Adelton. Num gesto de compaixão com os velhos moradores, o já então centenário Eulálio e a filha, o pastor Adelton ofereceu "um teto provisório". "Tratava-se de uma casa de um só cômodo pegada à sua igreja nos arredores da cidade" (Buarque, 2009, p. 176).

A narração de Eulálio para essa migração é emblemática. A outra paisagem se descortina, conforme o seguinte trecho: "A diferença era que ao nosso redor a cidade agora não acabava mais, grassavam casebres de alvenaria crua e sem telhado, onde antes havia clubes campestres e chácaras aprazíveis" (Buarque, 2009, p. 177). A perplexidade de Maria Eulália com a precariedade das habitações e com os novos vizinhos merece do pai um comentário: "São os pobres, expliquei, mas para minha filha eles podiam ao menos se dar o trabalho de caiar suas casas, plantar umas orquídeas" (p. 177).

$\mathrm{O}$ valão era um rio quase estagnado de tão lamacento, quando se deslocava dava a impressão de arrastar consigo as margens imundas. Era um rio podre, contudo eu ainda via alguma graça ali onde ele fazia a curva, no modo peculiar daquela curva, penso que a curva é o gesto do rio. E assim o reconheci, como às vezes se reconhece num homem velho o trejeito infantil, mais lento apenas. Aquele era o ribeirão da minha fazenda na serra raiz (Buarque, 2009, p. 177-178).

O périplo descensional se completa com o retorno à terra que esconde os escombros da fazenda da "feliz infância". Descendente direto da aristocracia rural, o corpo envelhecido e pauperizado de Eulálio serve como metáfora de uma classe senhorial descentrada. Por isso mesmo, é compreensível sua confissão: “[...] me trouxe um certo conforto saber que debaixo do meu chão estava o cemitério onde meu avô repousava" (Buarque, 2009, p. 178). Em outra passagem, o narrador chega até a brincar que de tanto o vira-lata cavoucar a terra, "exumaria os ossos do meu avô, e de lambuja os de Balbino seu escravo" (p. 179).

No banheiro dessa casa modesta, Eulálio buscará a "derradeira visão de Matilde" (Buarque, 2009, p. 137), esfregando-se contra a parede chapiscada, a fim de espreitar a imagem fugidia de sua esposa ausente. O narrador assevera: "Digo aos senhores que conheci o vasto mundo, vi 
paisagens sublimes, obras-primas, catedrais, mas ao fim e ao cabo meus olhos não têm recordação mais vívida que a de uns cavalos-marinhos nos azulejos do meu banheiro" (p. 180). Atrás dessa visagem, desequilibra-se, quebrando a perna direita. Conduzido ao hospital público, Eulálio devaneia, narra sua vida, buscando alcançar a sombra de Matilde.

Matilde, essa personagem "feita de quase nada" (Schwarz, 2009), de hábitos culturais considerados reles pelo marido, assombra a narrativa. Não por acaso, Matilde é aquela "escurinha" que foi criada "como se fosse da família" (Buarque, 2009, p. 192), que escolhe verter o leite a amamentar a filha de Eulálio. Matilde é um fantasma da República, um fantasma que fala dos desejos e das repulsas da narrativa engendrada pela República, deixando visível o "espaço liminar de significação, que é marcado internamente pelos discursos de minorias, pelas histórias heterogêneas de povos em disputa por autoridades antagônicas e por locais tensos de diferença cultural" (Bhabha, 2005, p. 209-210).

Os fantasmas sempre retornam para exigir que se cumpram as promessas republicanas, rejeitando a oligárquica modernidade política brasileira e os ditames positivistas que garantem sua "ordem e progresso" e que mantêm sempre invisíveis, ou à margem, as demandas históricas dos vencidos por renovação e por justiça social efetivas.

\section{Referências}

ASSIS, Machado de (2008). Memórias póstumas de Brás Cubas. Obra completa. Rio de Janeiro: Nova Aguilar.

BACHELARD, Gaston (1978). A poética do espaço. Coleção Os pensadores São Paulo: Abril Cultural.

BENJAMIN, Walter (1984). Alegoria e drama barroco. In: Origem do drama barroco alemão. Tradução de Sergio Paulo Rouanet. São Paulo: Brasiliense.

(1994). Magia e técnica, arte e política: ensaios sobre literatura e história da cultura. Obras escolhidas, vol. 1. Tradução de Sergio Paulo Rouanet. 7. ed. São Paulo: Brasiliense.

BHABHA, Homi (2005). O local da cultura. Belo Horizonte: Editora UFMG.

BIGNOTTO, Newton (org.) (2000). Pensar a República. Belo Horizonte: Editora UFMG. 
BOSI, Ecléa (1987). Memória e sociedade: lembranças de velhos. São Paulo: T. A. Queiroz, EDUSP.

BUARQUE, Chico (2009). Leite derramado. São Paulo: Companhia das Letras.

CANDIDO, Antonio (1979). Introdução. In: MICELI, Sérgio. Intelectuais e classe dirigente no Brasil (1920-1945). São Paulo: Difel.

CHATTERJEE, Partha (2004). Colonialismo, modernidade e politica. Salvador: Edufba, CEAO.

CURY, Maria Zilda Ferreira (2007). Novas geografias narrativas. Letras de hoje, Porto Alegre, v. 42, n. 4, p. 7-17.

FOUCAULT, Michel (1999). Em defesa da sociedade: curso no Collège de France (1975-1976). São Paulo: Martins Fontes.

(2008). Segurança, território, população: curso dado no Collège de France (1977-1978). São Paulo: Martins Fontes.

(2009). Outros espaços. In: Estética: literatura e pintura, música e cinema. Coleção Ditos e escritos, v. III. Rio de Janeiro: Forense Universitária.

GAGNEBIN, Jeanne-Marie (1994). História e narração em Walter Benjamin. Campinas: Editora da Unicamp; São Paulo: Perspectiva.

HOMEM, Wagner (2009). Histórias de canções: Chico Buarque. São Paulo: Leya.

ISER, Wolfgang (1996). O fictício e o imaginário: perspectiva de uma antropologia literária. Rio de Janeiro: EdUERJ.

LIMA, Ludmylla Mendes (2010). Machado de Assis, um pós-iluminista precoce. In: JORNADAS ANDINAS DE LITERATURA LATINO-AMERICANA, 9., Rio de Janeiro, 2 a 6 ago.

MIGNOLO, Walter D. (1995). Globalização, processos de civilização, línguas e culturas. Cadernos CRH, Salvador, n. 22, p. 9-30.

NABUCO, Joaquim (1900). Minha formação. Rio de Janeiro: Garnier. Disponível em: <http://www.brasiliana.usp.br/bbd/handle/1918/01206700>. Acesso em: 12 jan. 2014.

(2003). O abolicionismo. Brasília: Senado Federal, Conselho Editorial.

NORA, Pierre (1993). Entre memória e história: a problemática dos lugares. Projeto história, São Paulo, n. 10, p. 7-28.

OLIVIERI-GODET, Rita (2010). Errância/migrância/migração. In: BERND, Zilá (org.) Dicionário das mobilidades culturais: percursos americanos. Porto Alegre: Literalis. 
SCHWARCZ, Lilia K. Moritz (2008). Apresentação: Imaginar é difícil (porém necessário). In: ANDERSON, Benedict. Comunidades imaginadas: reflexões sobre a origem e a difusão do nacionalismo. Tradução de Denise Bottman. São Paulo: Companhia das Letras.

SCHWARZ, Roberto (2009). Brincalhão, mas não ingênuo. Folha de S. Paulo, São Paulo, 28 mar. Ilustrada, p. 6-7. Disponível em: http://www.chicobuarque.com.br/critica/crit_leite_fsp_SCHWARZ.htm. Acesso em: 31 jul. 2013.

SOMMER, Doris (2004). Ficções de fundação: os romances nacionais da América Latina. Belo Horizonte: Editora UFMG.

SONTAG, Susan (2007). Doença como metáfora/AIDS e suas metáforas. São Paulo: Companhia das Letras.

Recebido em dezembro de 2012.

Aprovado em junho de 2013.

\section{resumolabstract}

\section{O baú da República: mobilidades e memórias em Leite derramado}

\section{Tatiana Sena}

$\mathrm{O}$ artigo analisa o entrelaçamento entre memória e espaço no romance Leite derramado, de Chico Buarque, argumentando que os decursos temporais e espaciais da trajetória do centenário narrador-protagonista, Eulálio Montenegro d'Assumpção, delineiam uma cartografia política do Brasil, com especial ênfase na modernidade republicana.

Palavras-chave: memória cultural, espaço, política republicana, Chico Buarque.

\section{The chest of the Republic: mobilities and memories in Leite derramado}

\section{Tatiana Sena}

The article examines the intertwining of memory and space in the novel Leite derramado, by Chico Buarque, arguing that the spatial mobilities and the temporalities in the trajetory of the centenary narrator-protagonist, Eulalio Montenegro d'Assumpcao, outline a political cartography of Brazil, with special emphasis on Republican modernity.

Keywords: cultural memory, space, republican politics, Chico Buarque. 